\title{
RETINITIS PIGMENTOSA WITH MACULAR DYSTROPHY. REPORT OF A FAMILIAL GROUP \\ BY
}

\author{
ARNOLD SORSBY
}

LONDON

IN an earlier communication (Brit. Jl. Ophthal., Vol. XXIV, p. 469, 1940 ), attention was drawn to the wide range of appearances seen in macular dystrophy. It was argued that the classical conception of a limited central lesion was not borne out by the actual data. In many cases there is considerable involvement of the peripheral zones, so much so that it was pointed out that to designate these cases as macular dystrophy is like speaking of retinitis pigmentosa as "equatorial degeneration of the retina"-an early and striking change rather than the whole picture would be stressed. The fine graduation of macular dystrophy into generalised dystrophy of the retina was exemplified by recorded cases in the literature showing retinitis pigmentosa with varied and early involvement of the central area, and a case was described (ibid., case 2, p. 485), showing clearly the association of typical retinitis pigmentosa with macular dystrophy of the atrophic type. In this particular case no hereditary or familial incidence could be established, so that there was some lack of validity in drawing on this case for an argument on clearly defined familial and hereditary lesions. The present note supplies the necessary validity, as it concerns a familial group showing the association of the two lesions.

Family history: Two of the four sons and one of the two daughters in this sibship are affected. The family is of consanguineous origin, the father being a cousin of the maternal grandfather. There were no miscarriages or early deaths in the sibship.

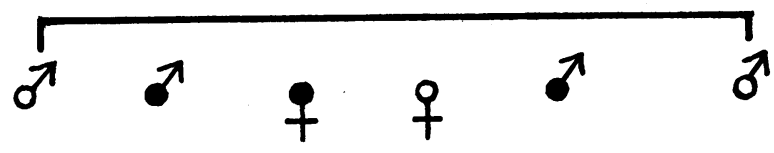

Personal histories: (1) Samuel $\mathrm{H}$, aged 37 years. Does not remember having any difficulty with distance or night vision till about the age of 20 years. Vision has deteriorated greatly during the past five years. At the present it is 6/60 in each eye with correction (R. +1.0 D.Sph. $0^{\circ}-2.0$ D.Cyl. $180^{\circ}$, L. -1.0 D.Sph. $0-1^{\circ} 0 \mathrm{D} . \mathrm{Cyl} \cdot 180^{\circ}$ ). The fields are contracted to the fixation point.

(2) Sarah $\mathrm{H}$, aged 34 years. Has always been conscious of night blindness, but vision has been sufficiently good so as not to 
interfere with philological studies at a university till seven years ago. Sight has deteriorated greatly during the last three years. Vision with correction: R. $6 / 36 \overline{\mathrm{c}}-8.0$ D.Sph. $0-0.5$ D.Cyl. $180^{\circ}$, L. $6 / 60 \overline{\mathrm{c}}-7.0$ D.Cyl. $\bigcirc-2.50$ D.Cyl. $180^{\circ}$. Fields extend $10^{\circ}-$ $15^{\circ}$ around fixation point. The patient suffers from duodenal ulcer.

Ophthalmoscopically both patients show essentially similar pictures. Typical bone-corpuscle pigment is distributed rather unevenly over the different sectors of the fundi, which also show gross pigmentation here and there. The discs and retinal arteries are characteristic of retinitis pigmentosa, and there is considerable unmasking of the choroidal circulation. (Figs. 1 and 2). The macular lesions correspond closely to those shown in Figs. 34 and 35 of the original communication.

The other affected member in this sibship could not be examined. His age is given as 28 years, and his difficulties appear to be of the same type as those experienced by his brother and sister. The parents and the unaffected sibs could also not be examined, as most of the members of this family reside in Poland. A cousin of the patients was seen and found normal.

This group may be taken as lending support to the view that macular dystrophy cannot be put in sharp antithesis to generalised

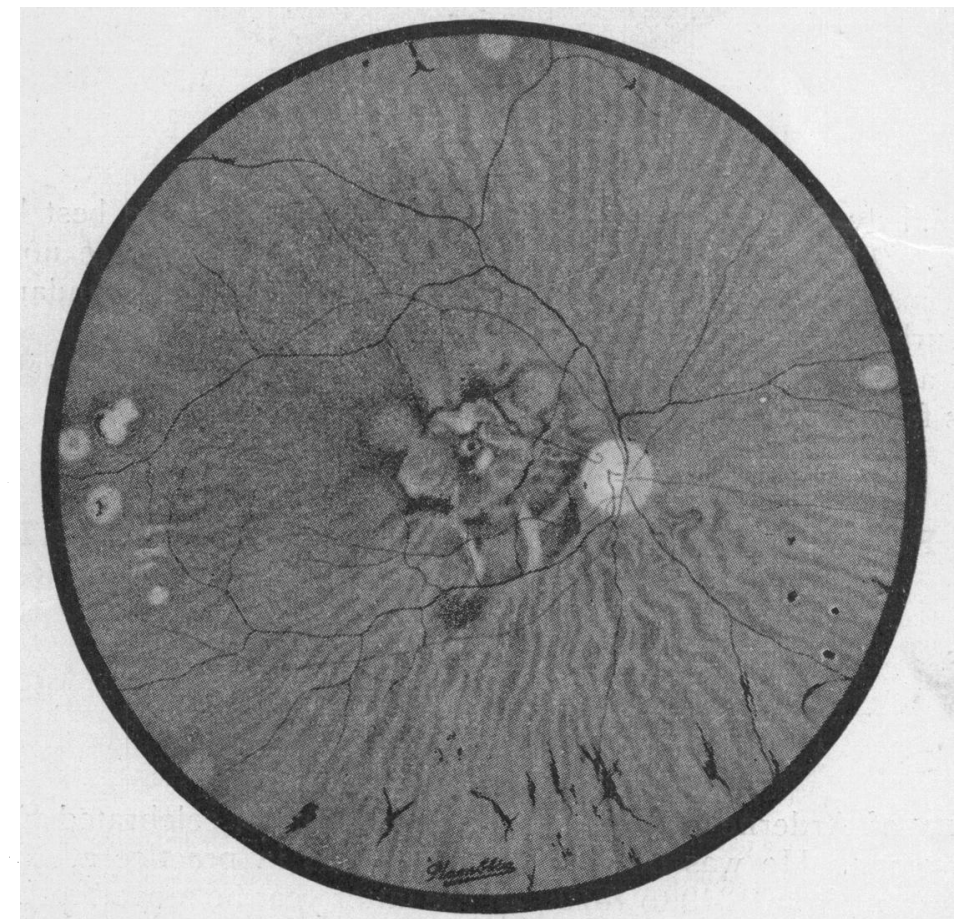

FIG. 1 . 


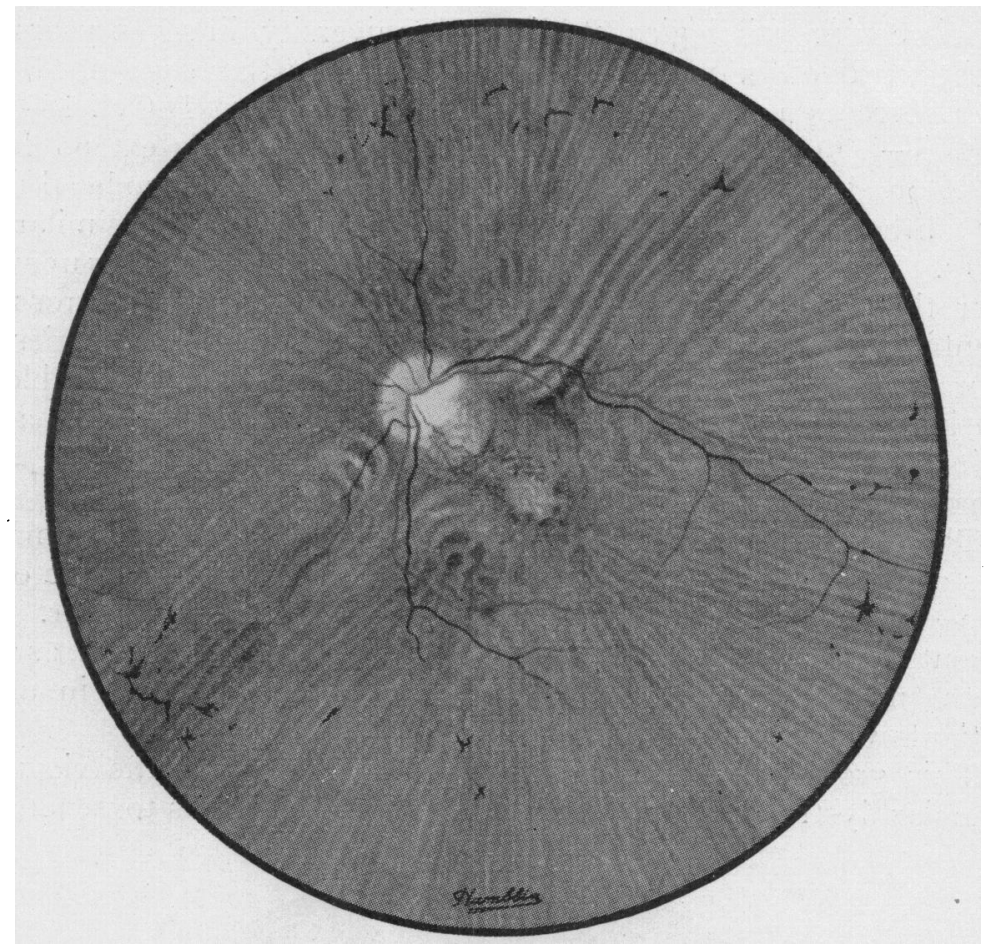

FIG. 2.

retinal dystrophy of which retinitis pigmentosa is the best known type. The various clinical types of retinal dystrophy are not rigid entities, but probably localised expressions of one fundamental disturbance.

I am indebted to Mr. F. A. Williamson-Noble for kindly referring this family to me.

\section{A FIFTEENTH CENTURY ENGLISH TRANSLATION OF JOHN OF ARDERNE'S de Cura Oculorum}

BY

$$
\begin{aligned}
& \text { R. R. JAMES } \\
& \text { WOODBRIDGE }
\end{aligned}
$$

JoHn of Arderne was the first of a long line of celebrated English surgeons. He was born in 1307 and was in practice at Newarkon-Trent from 1349 to 1370 . In the latter year he moved to London and in 1377 he wrote his booklet which forms the subject of this 